\title{
PENGARUH PRENATAL YOGA TERHADAP TINGKAT KECEMASAN IBU HAMIL PRIMIGRAVIDARUM TRIMESTER III DI KEDIRI
}

\author{
Rahma Kusuma Dewi ${ }^{1}$,Weni Tri Purnani ${ }^{2}$ \\ ${ }^{1,2}$ Program Studi D-IV Bidan Pendidik, Fakultas Ilmu Kesehatan, Universitas Kadiri \\ rkusde@gmail.com
}

\begin{abstract}
The Pregnant women anxiety will effect the physically and fisically's condition of baby and mother. The anxiety can be caused by the long duration of labour process especially primigravidarum pregnancy women. The Purpose to know the influence of yoga prenatal toward the anxiety level of third semester primigravidarum mother. The Method of this research study was pre post test control group. The samples were 32 respondent, consist of 16 treatment group and 16 control group. This research used wilcoxon test to analyze the data. The Result of the research shows the influence of yoga prenatal toward the anxiety level of trimester III primigravidarum pregnancy women in Puskesmas Bangsongan of treatment group $(p<0.05)$; there were no influence of yoga prenatal toward the anxiety level of trimester III primigravidarum pregnancy women in Puskesmas Bangsongan of control group ( $p>0.05)$ and there were the different anxiety of trimester III primigravidarum pregnant women anxiety level before and after yoga prenatal in Puskesmas Bangsongan ( $p=0.000)$. Thus, it Concluded that yoga prenatal influences to decrease the anxiety of trimester III primigravidarum pregnant woman's anxiety level.
\end{abstract}

Keywords: yoga prenatal, anxiety, pregnant woman, primigravidarum

\begin{abstract}
ABSTRAK
Kecemasan pada ibu hamil akan memberi dampak terhadap kondisi fisik dan psikis ibu dan janin. Kecemasan pada kehamilan bisa muncul karena masa penantian yang panjang dalam menunggu proses persalinan terutama pada ibu hamil primigravidarum .Tujuan untuk mengetahui pengaruh prenatal yoga terhadap tingkat kecemasan ibu hamil primigravidarum trimester III. Metode penelitian ini merupakan pre- experiment dengan pre-post test control group. Besar sampel dalam penelitian adalah 32 responden yang terdiri dari 16 kelompok perlakuan dan 16 kelompok kontrol. Analisis yang digunakan adalah uji Wilcoxon. Hasilnya terdapat pengaruh prenatal yoga terhadap tingkat kecemasan ibu hamil primigravidarum trimester III di Wilayah Kerja Puskesmas Bangsongan pada kelompok perlakuan $(\mathrm{p}<0,05)$; tidak terdapat pengaruh prenatal yoga terhadap tingkat kecemasan ibu hamil primigravidarum trimester III di Wilayah Kerja Puskesmas Bangsongan ( $p>0.05)$ pada kelompok kontrol, dan terdapat perbedaan tingkat kecemasan ibu hamil primigravida trimester III sebelum dan sesudah prenatal yoga di Wilayah Kerja Puskesmas Bangsongan( $\mathrm{p}=0,000)$.Kesimpulan Prenatal Yoga berpengaruh dalam menurunkan tingkat kecemasan ibu hamil primigravidarum trimester III.
\end{abstract}

Kata Kunci: Prenatal Yoga, Kecemasan, ibu hamil, primigravidarum 
Rahma, et.al. Pengaruh Prenatal Yoga Terhadap Tingkat Kecemasan Ibu Hamil Primigravidarum Trimester III di Kediri

\section{PENDAHULUAN}

Kehamilan merupakan masa terjadinya perubahan yang besar dalam tubuh seorang perempuan. Perubahan ini tidak hanya berhubungan dengan bentuk dan berat badan, tetapi juga perubahan biokimia, fisiologis, bahkan emosional yang merupakan konsekuensi dari pertumbuhan janin dalam rahim (Emilia, 2010). Kecemasan akan dirasakan berbeda selama kehamilan dan kecemasan trimester ketiga lebih tinggi dibanding trimester sebelumnya (Varney,et al., 2010). Kecemasan dan depresi di negara maju sekitar $7-20 \%$ dan di negara berkembang lebih dari 20\% (Biaggi, et al., 2016).

Pada dasarnya Ibu hamil akan mengalami beberapa perubahan dalam tubuhnya, baik dalam segi fisiologis dan psikologis. Selama proses perubahan tersebut secara psikologis ibu hamil akan menyesuaikan dengan perubahan baru yang ada dalam dirinya sehingga hal ini juga dapat menimbulkan kecemasan (Aprianawati, R.B $\&$ Sulistyorini, 2007). Olahraga yang teratur dalam masa kehamilan sangat diperlukan bagi ibu hamil. Beberapa olahraga yang dapat dilakukan oleh ibu hamil antara lain senam hamil, jalan kaki, senam air, dan yoga. Prenatal Yoga adalah modifikasi dari yoga klasik yg telah disesuaikan dengan kondisi wanita hamil yg dilakukan dengan intensitas yang lebih lembut dan perlahan (Sindhu, 2009). Prenatal Yoga dapat menurunkan stress,meningkatkan kualitas hidup, memberi rasa nyaman, mengurangi nyeri persalinan (Curtis, et al., 2012)

Berdasarkan penjelasan tersebut, peneliti tertarik untuk meneliti "Pengaruh Prenatal Yoga Terhadap Tingkat Kecemasan Ibu Hamil Primigravidarum Trimester III Di Wilayah Kerja Puskesmas Bangsongan Kabupaten Kediri Tahun 2018”.

\section{METODE}

Dalam penelitian ini termasuk jenis penelitian inferensial kuantitatif, Metode penelitian ini menggunakan pendekatan Pretest-posttest Control Group Design (Arikunto,2010). Penelitian ini dilakukan dengan cara memberikan pre test (pengamatan awal) terlebih dahulu sebelum diberikan perlakuan (x) setelah diberikan
JPH RECODE Oktober 2018; 2 (1) : 76-82 http://e-journal.unair.ac.id/JPHRECODE

perlakuan, kemudian dilakukan kembali post test (pengamatan akhir) hal ini dilakukan untuk perbedaan yang dihasilkan antara pre test dan post test. Populasi dalam penelitian ini adalah seluruh ibu hamil primigravidarum trimester III di Wilayah Kerja Puskesmas Bangsongan Kabupaten Kediri sejumlah 36 ibu hamil primigravidarum tirmester III. Jumlah sampel dihitung menggunakan rumus (Lwanga,S.K., \& Lemeshow, 1991). Besar sampel dalam penelitian ini adalah 32 responden. Teknik sampling yang digunakan dalam penelitian ini adalah simple random sampling. Instrumen yang digunakan dalam penelitian ini adalah Hamilton Anxiety Rating Scale (HARS. Analisis data penelitian ini diantaranya analisis univariat dan bivariat. Analisis univariat bertujuan untuk menganalisis distribusi frekuensi karakteristik umur, pendidikan, pekerjaan dan abortus. Analisis bivariat untuk mengetahui tingkat kecemasan menggunakan Mann Whitney Test dan untuk mengetahui pengaruh menggunakan uji wilcoxon. 


\section{HASIL}

Tabel 1. Distribusi Frekuensi Karakteristik Responden Berdasarkan Umur pada kelompok Perlakuan di Wilayah Kerja Puskesmas Bangsongan Kabupaten Kediri Tahun 2018

\begin{tabular}{|l|l|l|}
\hline \multicolumn{1}{|c|}{ Usia } & \multicolumn{1}{|c|}{ Frekuensi (n) } & \multicolumn{1}{c|}{ Persentase (\%) } \\
\hline$<20$ tahun & 0 & 0 \\
$20-35$ tahun & 16 & 100 \\
$>35$ tahun & 0 & 0 \\
\hline Jumlah & 16 & 100 \\
\hline
\end{tabular}

Berdasarkan tabel 1 di atas dapat diketahui bahwa seluruh responden (100\%) memiliki usia 20- 35 tahun yaitu sebanyak 16 responden.

Tabel 2. Distribusi Frekuensi Karakteristik Responden Berdasarkan Umur pada kelompok kontrol di Wilayah Kerja Puskesmas Bangsongan Kabupaten Kediri Tahun 2018

\begin{tabular}{|l|l|l|}
\hline \multicolumn{1}{|c|}{ Usia } & \multicolumn{1}{|c|}{ Frekuensi (n) } & \multicolumn{1}{c|}{ Persentase (\%) } \\
\hline$<20$ tahun & 1 & 6,2 \\
$20-35$ tahun & 15 & 93,8 \\
$>35$ tahun & 0 & 0 \\
\hline Jumlah & 16 & 100 \\
\hline
\end{tabular}

Berdasarkan tabel 2 di atas diketahui bahwa hampir seluruh respoden (93.8\%) memiliki usia 20-35 tahun yaitu sebanyak 15 responden.

Tabel 3. Distribusi Frekuensi Karakteristik Responden Berdasarkan Pendidikan pada kelompok Perlakuan di Wilayah Kerja Puskesmas Bangsongan Kabupaten Kediri Tahun 2018

\begin{tabular}{|l|l|l|}
\hline \multicolumn{1}{|c|}{ Pendidikan } & \multicolumn{1}{|c|}{ Frekuensi (n) } & \multicolumn{1}{c|}{ Persentase (\%) } \\
\hline Dasar (SD dan SMP) & 0 & 0,0 \\
Menengah (SMA) & 13 & 81,2 \\
Tinggi (PT) & 3 & 18,8 \\
\hline Jumlah & 16 & 100 \\
\hline
\end{tabular}

Berdasarkan tabel 3 di atas dapat diketahui hampir seluruhnya (90\%) berpendidikan menengah (SMA) yaitu sebanyak 13 responden. 
Rahma, et.al. Pengaruh Prenatal Yoga Terhadap Tingkat Kecemasan Ibu Hamil Primigravidarum Trimester III di Kediri
JPH RECODE Oktober 2018; 2 (1) : 76-82 http://e-journal.unair.ac.id/JPHRECODE

Tabel 4. Distribusi Frekuensi Karakteristik Responden Berdasarkan Pendidikan pada kelompok Kontrol di Wilayah Kerja Puskesmas Bangsongan Kabupaten Kediri Tahun 2018

\begin{tabular}{|l|l|l|}
\hline \multicolumn{1}{|c|}{ Pendidikan } & \multicolumn{1}{|c|}{ Frekuensi (n) } & \multicolumn{1}{c|}{ Persentase (\%) } \\
\hline Dasar (SD dan SMP) & 0 & 0,0 \\
Menengah (SMA) & 13 & 81,2 \\
Tinggi (PT) & 3 & 18,8 \\
\hline Jumlah & 16 & 100 \\
\hline
\end{tabular}

Tabel tersebut menunjukkan bahwa hampir seluruhnya (90\%) berpendidikan menengah (SMA) yaitu sebanyak 13 responden.

Tabel 5. Distribusi Frekuensi Karakteristik Responden BerdasarkanPekerjaan pada kelompok Perlakuan di Wilayah Kerja Puskesmas Bangsongan Kabupaten Kediri Tahun 2018

\begin{tabular}{|l|l|l|}
\hline \multicolumn{1}{|c|}{ Pekerjaan } & \multicolumn{1}{|c|}{ Frekuensi (n) } & \multicolumn{1}{c|}{ Persentase (\%) } \\
\hline IRT & 11 & 68,8 \\
Wiraswasta & 5 & 31,2 \\
Pegawai Swasta & 0 & 0,0 \\
PNS & 0 & 0,0 \\
\hline Jumlah & 16 & 100 \\
\hline
\end{tabular}

Berdasarkan tabel 5 di atas dapat diketahui sebagian besar (68.8\%) sebagai IRT atau ibu rumah tangga yaitu sebanyak 11 responden.

Tabel 6. Distribusi Frekuensi Karakteristik Responden Berdasarkan Pekerjaan pada kelompok Kontrol di Wilayah Kerja Puskesmas Bangsongan Kabupaten Kediri Tahun 2018

\begin{tabular}{|l|l|l|}
\hline \multicolumn{1}{|c|}{ Pekerjaan } & \multicolumn{1}{c|}{ Frekuensi (n) } & \multicolumn{1}{c|}{ Persentase (\%) } \\
\hline IRT & 9 & 56,2 \\
Wiraswasta & 7 & 43,8 \\
Pegawai Swasta & 0 & 0,0 \\
PNS & 0 & 0,0 \\
\hline Jumlah & 16 & 100 \\
\hline
\end{tabular}

Berdasarkan tabel 6 di atas dapat diketahui sebagian besar responden (56.2\%) sebagai IRT atau ibu rumah tangga yaitu sebanyak 9 responden. 
Rahma, et.al. Pengaruh Prenatal Yoga Terhadap Tingkat Kecemasan Ibu Hamil Primigravidarum Trimester III di Kediri
JPH RECODE Oktober 2018; 2 (1) : 76-82 http://e-journal.unair.ac.id/JPHRECODE

Tabel 7. Pengaruh Prenatal Yoga Terhadap Tingkat Kecemasan Ibu Hamil Primigravida Trimester III pada Kelompok Perlakuan antara saat Pre Test dan Post Test Di Wilayah Kerja Puskesmas Bangsongan Kabupaten Kediri Tahun 2018

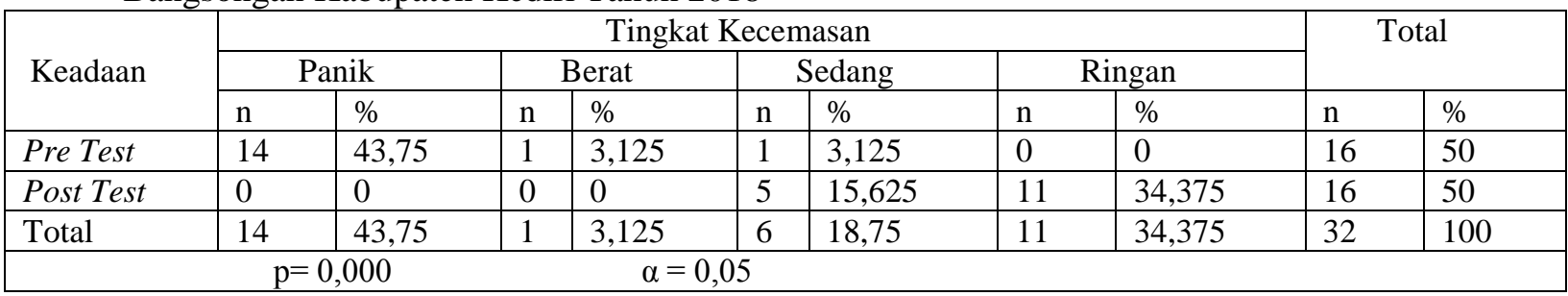

Berdasarkan hasil pengujian menunjukkan hasil uji perbedaan tingkat kecemasan ibu hamil primigravida trimester III pada kelompok perlakuan antara saat pre test mempunyai nilai signifikansi (p) sebesar 0,000 yang lebih kecil dari alpha 0,05, sehingga Ho ditolak dan dapat disimpulkan bahwa terdapat perbedaan tingkat kecemasan ibu hamil primigravida trimester III yang signifikan (bermakna) pada kelompok perlakuan antara pada saat pre test dengan post test.

Tabel 8. Pengaruh Prenatal Yoga Terhadap Tingkat Kecemasan Ibu Hamil Primigravida Trimester III pada saat Pre Test antara Kelompok Perlakuan dan Kelompok Kontrol Di Wilayah Kerja Puskesmas Bangsongan Kabupaten Kediri Tahun 2018

\begin{tabular}{|c|c|c|c|c|c|c|}
\hline \multirow{3}{*}{$\begin{array}{c}\text { Tingkat } \\
\text { Kecemasan }\end{array}$} & \multicolumn{4}{|c|}{ Kelompok } & \multirow{2}{*}{\multicolumn{2}{|c|}{ Total }} \\
\hline & \multicolumn{2}{|c|}{ Prenatal Yoga } & \multicolumn{2}{|c|}{ Kontrol } & & \\
\hline & $\mathrm{n}$ & $\%$ & $\mathrm{n}$ & $\%$ & $n$ & $\%$ \\
\hline Panik & 14 & 43,75 & 10 & 3,125 & 24 & 75 \\
\hline Berat & 1 & 3,125 & 5 & 15,625 & 6 & 18,75 \\
\hline Sedang & 1 & 3,125 & 1 & 3,125 & 2 & 6,25 \\
\hline Total & 16 & 50 & 16 & 3,125 & 32 & 100 \\
\hline \multicolumn{5}{|c|}{$p=0,27$} & & \\
\hline
\end{tabular}

Untuk hasil analisa data dengan menggunakan Uji Mann whitney menunjukkan hasil uji perbedaan tingkat kecemasan ibu hamil primigravida trimester III pada saat pre test antara kelompok kontrol dan kelompok perlakuan mempunyai nilai signifikansi (p) sebesar 0.270 yang lebih besar dari alpha 0.05 , sehingga Ho diterima dan dapat disimpulkan bahwa tidak terdapat perbedaan tingkat kecemasan ibu hamil primigravida trimester III pada saat pre test antara kelompok kontrol dan kelompok perlakuan.

Tabel 8. Pengaruh Prenatal Yoga Terhadap Tingkat Kecemasan Ibu Hamil Primigravida Trimester III pada saat Post Test antara Kelompok Perlakuan dan Kelompok Kontrol Di Wilayah Kerja Puskesmas Bangsongan Kabupaten Kediri Tahun 2018

\begin{tabular}{|c|c|c|c|c|c|c|}
\hline \multirow{3}{*}{$\begin{array}{c}\text { Tingkat } \\
\text { Kecemasan }\end{array}$} & \multicolumn{4}{|c|}{ Kelompok } & \multirow{2}{*}{\multicolumn{2}{|c|}{ Total }} \\
\hline & \multicolumn{2}{|c|}{ Prenatal Yoga } & \multicolumn{2}{|c|}{ Kontrol } & & \\
\hline & $\mathrm{n}$ & $\%$ & $\mathrm{n}$ & $\%$ & $\mathrm{n}$ & $\%$ \\
\hline Panik & 0 & 0 & 8 & 25 & 8 & 25 \\
\hline Berat & 0 & 0 & 6 & 18,75 & 6 & 18,75 \\
\hline Sedang & 5 & 15,625 & 2 & 6,25 & 7 & 21,875 \\
\hline Ringan & 11 & 34,375 & 0 & 0 & 11 & 34,375 \\
\hline Total & 16 & 50 & 16 & 50 & 32 & 100 \\
\hline \multicolumn{5}{|c|}{$p=0,27$} & & \\
\hline
\end{tabular}


Rahma, et.al. Pengaruh Prenatal Yoga Terhadap Tingkat Kecemasan Ibu Hamil Primigravidarum Trimester III di Kediri

Untuk hasil analisa data dengan menggunakan Uji Mann whitney menunjukkan hasil uji perbedaan tingkat kecemasan ibu hamil primigravida trimester III pada saat post test antara kelompok yang kontrol dan kelompok yang mendapatkan perlakuan mempunyai nilai signifikansi (p) sebesar 0.000 yang lebih kecil dari alpha 0.05 , sehingga Ho ditolak dan dapat disimpulkan bahwa terdapat perbedaan tingkat kecemasan ibu hamil primigravida trimester III pada saat post test antara kelompok kontrol dan kelompok perlakuan. Dimana pada ibu hamil primigravida trimester III yang mendapatkan prenatal yoga mempunyai tingkat kecemasan yang lebih rendah daripada tingkat kecemasan ibu hamil pada kelompok kontrol. Hal ini menunjukkan adanya pengaruh pemberian prenatal yoga pada ibu hamil dapat menurunkan tingkat kecemasan mereka.

\section{PEMBAHASAN}

Berdasarkan hasil penelitian dapat diketahui yang mendapatkan prenatal yoga, pada saat pre test ada sebanyak 14 orang ibu yang tingkat kecemasannya tergolong panik, 1 orang ibu mempunyai tingkat kecemasan tergolong berat, sedangkan 1 orang ibu hamil lainnya mempunyai tingkat kecemasan yang tergolong sedang. Pada saat post test sebanyak 5 orang ibu yang tingkat kecemasannya tergolong sedang, 11 orang ibu mempunyai tingkat kecemasan yang tergolong ringan,. Berdasarkan hasil uji statistik dengan menggunakan uji wilcoxon diketahui bahwa besarnya $p$-value 0,000 lebih kecil dari nilai $\alpha$ $=0,05$ sehingga $\mathrm{H}_{0}$ ditolak, dapat disimpulkan bahwa terdapat perbedaan Tingkat Kecemasan Ibu Hamil Primigravida Trimester III yang signifikan pada kelompok perlakuan antara pada saat pre test dan post test.

Kecemasan dapat terjadi akibat tinggi rendahnya tingkat pendidikan yang dimiliki seseorang. Ibu hamil yang memiliki pengetahuan yang tinggi dengan tingkat pendidikan yang lebih tinggi bisa mengatasi kehamilannya dengan baik bila dibandingkan yang tidak memiliki dengan tingkat pendidikan yang rendah (Zanden, et al., 2007). Mayoritas tingkat pendidikan dalam kedua kelompok adalah berpendidikan SMA
JPH RECODE Oktober 2018; 2 (1) : 76-82 http://e-journal.unair.ac.id/JPHRECODE

$(81,2 \%)$

Menurut Rokhmah (2008) masa kehamilan merupakan peristiwa yang membahagiakan dalam kehidupannya, namun terkadang ibu hamil juga mengalami kecemasan, kecemasan tersebut dikarenakan adanya perubahan fisik dan psikologis yang membuat ibu hamil merasa ketakutan tentang hal-hal yang terjadi selama kehamilan. Prenatal yoga adalah sebuah ilmu yang menjelaskan kaitan antara fisik mental dan spiritual manusia untuk mencapai kesehatan yang menyeluruh (Sindhu, 2009). Melakukan latihan yoga pada saat hamil akan mempersiapkan tubuh maupun pikiran untuk siap dan tegar menghadapi masa persalinan (Wiadnyana, 2010).

Menurut pendapat peneliti kecemasan seseorang dipengaruhi oleh banyak hal, selain yoga antenatal faktor penting yang dapat membantu menurunkan kecemasan adalah dukungan keluarga yang dapat berupa dukungan dari suami, orang tua atau keluarga yang lain. Berdasarkan hal tersebut, upaya yang dapat dilakukan agar ibu hamil tidak mudah untuk mengalami kecemasan yaitu perlu dilakukan kegiatan prenatal yoga agar selama proses hamil hingga melahirkan ibu hamil tidak mengalami kesulitan.

Manfaat kegiatan yoga bagi kesehatan tubuh yaitu diantaranya dapat menurunkan tekanan darah, detak jantung, meningkatkan dan peredaran darah dalam proses membuang sisa-sisa makanan yang mengandung racun bagi tubuh. Kemudian, beberapa manfaat senam hamil yoga bagi ibu hamil yaitu dapat meningkatkan aliran darah dan nutrisi janin secara adequate, serta berperan dalam kesehatan organ reproduksi dan panggul seperti memperkuat otot perineum dalam mempersiapkan kelahiran bayi secara alami (Stoppard, 2008).

\section{KESIMPULAN DAN SARAN Kesimpulan}

Penelitian menunjukkan bahwa tingkat kecemasan ibu hamil primigravidarum pada trimester III yang mendapatkan prenatal yoga lebih rendah dibandingkan dengan ibu hamil primigravidarum trimester III yang tidak mendapatkan prenatal yoga. 
Rahma, et.al. Pengaruh Prenatal Yoga Terhadap Tingkat Kecemasan Ibu Hamil Primigravidarum Trimester III di Kediri

\section{Saran}

Bagi ibu hamil diharapkan berperan aktif dalam melakukan olahraga secara rutin seperti prenatal yoga untuk mengurangi tingkat kecemasan. Bagi pelayanan kesehatan untuk mensosialisasikan pada ibu hamil bahwa prenatal yoga merupakan salah satu olahraga yang dapat dilakukan secara rutin.

\section{DAFTAR PUSTAKA}

Aprianawati, R.B \& Sulistyorini, I. R. 2007. Hubungan Dukungan Keluarga dengan Kecemasan Ibu Hamil Menghadapi Kelahiran Anak Pertama pada Masa Triwulan Ketiga.

Biaggi, A.,Conroy, S.,Pawlby, S.\& Pariante, C. 2016. Identifying the women ar risk of antenatal anxiaety and depression: a systematic review. L Affect Disord, 191:62- 77.

Curtis, K.,Weinrib, A. \& Katz, J. 2012. Systematic review of yoga for pregnant women: current status and future directions. Evid Based Complement Alternat Med, 2012: 1-13.

Emilia, O. 2010. Tetap bugar dan enegik selama hamil. Jakarta: Agra media pustaka.

Lwanga,S.K., L. S. 1991. Sample Size Determination In Health Studies. A Practical Manual. Geneva: World Health Organization (WHO), 1998. Role of the pharmacist in the health care system. Netherlands.

Rokhmah, R. N. 2008. Hubungan Meditasi Yoga dengan Daya Tahan Terhadap Stress Pada Paguyuban Yogi Waran Surakarta. Skripsi, Universitas Muhammadiyah, Surakarta.

Sindhu, P. 2009. Yoga Untuk Kehamilan Sehat, Bahagia, dan Penuh Makna. Seri Bugar. Bandung: Qonita, Mizan Pustaka.

Stoppard, M. 2008. Conception Pregnancy and Birth: Ensiklpoedia Kehamilan. Ensiklpoedia Kehamilan. Surabaya: Erlangga.

Varney, H.,Kriebs,J.M. \& Gegor, C. L.. 2010. Varney's midwifery. Fourth edition. Jakarta: EGC.

Wiadnyana, M.. 2010. The power of yoga for pregnancy and post pregnancy. Gramedia widiasarana. Jakarta: Taruna
JPH RECODE Oktober 2018; 2 (1) : 76-82 http://e-journal.unair.ac.id/JPHRECODE

Grafika.

Zanden, J. V., Crandell, T. L. \& Crandell, C. H. 2007. Human Development. Eight Edition. New York: Mc. Graw Hill 